\title{
ANÁLISE DO “PROGRAMA MULHERES MIL” NO IFPR, CAMPUS PARANAVAÍ: A TRANSFORMAÇÃO SOCIAL DE MULHERES EM BUSCA DA IGUALDADE DE GÊNERO
}

\author{
R. S. PANARIR-ANTUNES*, G. F. M. SOUZA, S. J. KLOSOSKI, J. B. DIAS JÚNIOR e F. L. G. FIGUEIRA \\ Instituto Federal do Paraná - Campus Paranavaí \\ renata.antunes@ifpr.edu.br*
}

Artigo submetido em setembro/2014 e aceito em dezembro/2015

DOI: $10.15628 /$ holos.2016.2418

\section{RESUMO}

O IFPR - Campus Paranavaí aderiu ao Programa Mulheres Mil em 2011. Durante a fase final dos cursos, foi realizada uma pesquisa para avaliação do Programa, que incluiu depoimento das alunas, pesquisa de evasão, e após o término, foi feito o acompanhamento de egressas. As entrevistas e pesquisas foram feitas por meio da aplicação de questionários. $O$ estudo teve como objetivo analisar a eficácia deste programa e a transformação social de mulheres em estado de vulnerabilidade social da cidade de Paranavaí. Os resultados demonstraram que os objetivos do Programa foram parcialmente cumpridos, contudo houve impacto positivo sobre as alunas concluintes, tais como recuperação da autoestima, aumento da escolaridade e profissionalização.

PALAVRAS-CHAVE: Mulheres em vulnerabilidade social; avaliação; impacto.

\section{"THOUSAND WOMEN PROGRAM" ANALYSIS IN IFPR, PARANAVAÍ CAMPUS: WOMEN'S SOCIAL TRANSFORMATION IN SEARCH FOR GENDER EQUALITY}

\begin{abstract}
IFPR - Paranavaí campus has adhered to the Thousand Women Program in 2011. During the courses'last phase, and evaluation research was done for the Program, that included the [female] students' testimony, evasion research, and after the end, a monitoring of the graduates was done. The interviews and researches were done by means of questionnaires. The study had as
\end{abstract}

objective to analyze the efficiency of this Program and the social transformation of women in state of social vulnerability of Paranavaí city. The results show that the Program's objectives were partially fulfilled, however, there was a positive effect on the graduates, such as recovery of self-worth, increase of the education level and professionalization.

KEYWORDS: Women in social vulnerability, evaluation, effect. 


\section{INTRODUÇÃO}

O Governo Brasileiro vem desenvolvendo um conjunto de prioridades de políticas públicas, especialmente nos eixos promoção da equidade, igualdade entre sexos, combate à violência contra mulher e acesso à educação. Integrado a essas prioridades, em 2007 surge o projeto piloto do Programa Mulheres Mil (BRASIL, 2013a). O Programa também contribuiu para o alcance das Metas do Milênio, promulgada pela ONU em 2000 e aprovada por 191 países. Entre as metas estabelecidas estão a erradicação da extrema pobreza e da fome, promoção da igualdade entre os sexos e autonomia das mulheres e garantia da sustentabilidade ambiental (BRASIL, 2012).

O Governo Federal desenvolveu inicialmente este programa para realizar uma qualificação profissional e tecnológica de cerca de mil mulheres desfavorecidas das regiões Nordeste e Norte. A meta era garantir o acesso à educação profissional e à elevação da escolaridade, de acordo com as necessidades educacionais de cada comunidade e a vocação econômica das regiões.

O programa está estruturado em três eixos - educação, cidadania e desenvolvimento sustentável - e possibilita a inclusão social, por meio da oferta de formação focada na autonomia e na criação de alternativas para a inserção no mundo do trabalho, para que essas mulheres consigam melhorar a qualidade de suas vidas e das de suas comunidades.

Porém, em 2009, o Ministério da Educação por meio da Secretaria de Educação Profissional e Tecnológica ( $\mathrm{Setec}$ ) decidiu expandir o programa para outras regiões do País, visando transformá lo em uma política pública a ser implementada em todos os Institutos Federais de Educação, Ciência e Tecnologia (Ifets) do país, ampliando a oferta para as mulheres desfavorecidas do Brasil.

A partir do ano de 2011 o IFPR - Campus de Paranavaí implantou o Programa Mulheres Mil na sua política de desenvolvimento, com o objetivo de atender 100 (cem) mulheres em estado de vulnerabilidade social no ano de 2012. Dois cursos de Formação Inicial e Continuada (FIC) foram ofertados: Auxiliar de Costura e Auxiliar de Cozinha.

Portanto, este estudo teve como objetivo analisar a eficácia do programa e seu impacto perante a vida de mulheres em estado de vulnerabilidade social na cidade de Paranavaí no Campus do IFPR. Visto que a cidade possui mais de $\mathbf{3 . 0 0 0}$ famílias cadastradas no Programa Bolsa Família e que carecem de assistência social, o Programa Mulheres Mil é mais uma oportunidade para qualificar e empregar mulheres de baixa renda. Desta forma, avaliar a eficácia do Programa e seu papel na transformação social é fundamental para dar continuidade ao projeto visando melhorias em sua execução e ao atendimento da demanda local.

\section{ALGUMAS RAZÕES DO PROGRAMA MULHERES MIL}

A questão do desemprego no Brasil tem atingido em grande parte o público feminino (OLIVEIRA et al., 2009), apesarda participação das mulheres no mundo do trabalho ter aumentado nos últimos anos (MADALOZZO et al., 2010). Segundo dados do Instituto Brasileiro de Geografia e Estatística - IBGE 2010, no ano de 2009, o percentual de mulheres desocupadas era superior $(56,5 \%)$ ao dos homens (43,5\%). Entre as mulheres desocupadas, apenas $31,7 \%$ frequentaram ou concluíram curso de qualificação profissional, sendo este número maior para os homens $(32,6 \%)$. O percentual de mulheres que possuía carteira assinada também foi menor, $47,2 \%$ contra $51,2 \%$ 
dos homens. Além disso, aquelas que são empregadas em carg os também ocupados por homens, enfrentam preconceito, e ganham menos, o que gera desigualdade salarial (OLIVEIRA \& ARRUDA, 2011). A faixa salarial média das mulheres é de $R \$ 1.097,93$ e a dos homens de $R \$ 1.518,93$. A situação é ainda mais agravante entre as mulheres negras, que arcam com a discriminação de cor e gênero, que é maior do que para os homens da mesma cor (SOARES, 2000).

As mulheres enfrentam dificuldades desde sua inserção no mundo do trabalho, baixos salários, ocupação de postos precários na contratação e progressão profissional, até a necessidade de conciliar os cuidados com filhos e afazeres domésticos, atividades que geralmente Ihe são encarregadas (SANCHES \& GEBRIM, 2003). Pesquisa realizada em 2001 mostra que os setores que mais empregaram mulheres foram aqueles com atividades que tem as mesmas características das funções exercidas em casa, como prestação de serviços e atividade social (SANCHES \& GEBRIM, 2003).

Além da taxa de desemprego ser maior entre as mulheres, o período que elas ficam desempregadas também é maior quando comparado aos homens. A maior empregabilidade feminina encontra-se em postos de trabalho vulneráveis, representados pelo trabalho sem registro, serviço doméstico, autônomos que trabalham para o público e trabalhadores familiares (SANCHES \& GEBRIM, 2003). Além disso, há diferença entre os padrões observados entre mulheres pobres e não pobres. A inatividade para mulheres de baixa renda é significativamente maior, o que pode estar associada a diferenças de escolaridade e provavelmente, dificuldades de acesso à creche (ABRAMO, 2004; OLIVEIRA et al., 2009).

Diante de um perfil de desigualdade de gênero vivenciado no mundo do trabalho, com um grande número de mulheres trabalhando na informalidade, ganhando menos que os homens, com baixa escolaridade, más condições de trabalho e muitas desempregadas, iniciativas do governo para tratar da questão de gênero e valorizar a mulher são de extrema importância, especialmente do público feminino de baixa renda e socialmente vulnerável.

A mulher é o ponto central das políticas públicas do Ministério do Desenvolvimento Social e Combate à Fome (MDS). A maioria delas tem no sexo feminino o foco de suas ações, por considerar que elas tomem a melhor decisão em benefício do grupo familiar. O Governo Brasileiro possui vários Programas voltados para população de baixa renda e alguns atingem em especial as mulheres. Entre eles está o Plano Brasil sem Miséria, que tem como foco de atuação milhões de brasileiros com renda familiar per capita inferior a $\mathrm{R} \$ 70$ mensais, e está baseado na garantia de renda, inclusão produtiva e no acesso aos serviços públicos (BRASIL, 2013b). O Bolsa Família integra o Plano Brasil Sem Miséria e tem priorizado a mulher como responsável por receber o benefício. Isto tem permitido maior inserção social e poder de compra, mais afirmação no espaço doméstico e ampliação do acesso a serviços públicos de educação e saúde. $O$ aumento da presença nas decisões do lar e da comunidade e a melhoria na qualidade de vida foram alguns dos impactos do Bolsa Família no dia-a-dia das mulheres. Várias famílias também são atendidas em Centros de Referência Social (CRAS), com um enfoque maior na figura da mulher.

Em 1983 foi criado o Programa Assistência Integral à Saúde da Mulher (PAISM), que oferece assistência de saúde para as mulheres em todas as etapas da vida (BRASIL, 1984). O programa dá ênfase a preocupações com doenças ginecológicas prevalentes, prevenção e tratamento de doenças sexualmente transmissíveis (DST) e Aids, além de assistência às mulheres vítimas de violência. No entanto, faltava um programa que atendesse a mulheres de baixa renda, com o 
objetivo de elevar a sua autoestima, promover a sua independência e qualificar para o mundo do trabalho, visto que tantas mulheres tem dificul dade de empregabilidade, e dentre os motivos estão a baixa renda, pouca escolaridade e falta de qualificação profissional. Visando atender este público e promover a igualdade de gêneros, surge em 2007, o Programa Mulheres Mil. O Programa é exclusivamente direcionado a mulheres de baixa renda, em situação de vulnerabilidade social, com o intuito de diminuir a desigualdade social e de gênero, elevar o grau de escolaridade, bem como promover uma formação profissional proporcionando a melhoria da qualidade de vida das mulheres atendidas e de suas famílias (BRASIL, 2013a).

Deste modo, a implantação do Programa Mulheres Mil no Campus de Paranavaí visa contribuir significativamente no processo de emancipação e empoderamento dessas mulheres, haja vista que são sujeitos ativos na construção de um novo itinerário de vida, pois participam de atividades que propiciam situações de aprendizagens concretas que estimulam a autovalorização, integração no mercado produtor, saberes e habilidades que foram desenvolvidas especificamente na área de cozinha e costura.

\section{METODOLOGIA DO PROGRAMA MULHERES MIL}

O objeto de estudo caracteriza-se pela avaliação da implantação do Programa Mulheres Mil no IFPR - Campus Paranavaí e de seu papel na transformação social de mulheres de baixa renda.

No ano de 2011 o IFPR - Campus de Paranavaí aderiu ao programa Mulheres Mil do Governo Federal oferecendo cem vagas para as mulheres de baixa renda e vulneráveis socialmente, com baixo índice de desenvolvimento humano, residentes nos bairros: Vila Alta, Morumbi e São Jorge. O processo seletivo efetivou-se em duas etapas, sendo a primeira avaliação de documentos e do questionário socioeconômico, e a segunda, uma entrevista, ambas de caráter classificatório. O resultado foi divulgado amplamente, por meio de chamadas nas emissoras de rádio locais, sites da cidade, bem como, nos murais do CRAS dos bairros selecionados e no IFPR Campus Paranavaí.

A cidade de Paranavaí, de acordo com no Censo do IBGE de 2012, possui 82.472 habitantes, sendo a maior cidade da Associação dos Municípios do Noroeste Paranaense-Amunpar. 0 município tem como limites o estado de São Paulo a norte e os municípios de Santo Antônio do Caiuá, São João do Caiuá e Alto Paraná a leste, Tamboara, Nova Aliança do Ivaí e Mirador a sul e Amaporã, Guairaçá e Terra Rica a oeste (IBGE, 2012).

Os bairros selecionados, conforme relatório do Centro de Referência de Assistência Social - (CRAS), apresentam problemas de infraestrutura, baixo índice de alfabetização, etc. Embora algumas famílias sejam assistidas pelo benefício social Bolsa Família, outros agravantes são marcantes e crescentes, como por exemplo, os índices de violência e criminalidade, sobretudo, causadas pelo aumento do consumo de drogas como o álcool e o crack, principalmente no bairro de Vila Alta.

Para verificar as transformações ocorridas durante a trajetória das mulheres do Programa, foram realizados depoimentos e acompanhamento de egressas após um ano de conclusão. Antes do depoimento, as alunas assinaram um Termo de Consentimento Livre e Esclarecido. 
Durante a execução do Programa algumas mulheres matriculadas que estavam frequentando as aulas foram entrevistadas, com uma única questão aberta, da qual as respostas foram gravadas e caracterizadas como depoimento.

Para o acompanhamento das egressas do Programa, foi elaborado um questionário para realização de uma pesquisa quantitativa, onde as ex-alunas foram entrevistadas via telefone.

\section{RESULTADOS E DISCUSSÕES}

Um total de 25 alunas foi entrevistado sobre a sua satisfação em relação ao Programa. Pela análise dos depoimentos constatou-se que todas as alunas se mostraram satisfeitas com o Programa e entre os itens citados em relação à avaliação do Mulheres Mil, estão: oportunidade para ter uma vida melhor, conhecimento, aprendizado, oportunidade de voltar a estudar, aumento da autoestima.

Um dos aspectos do Programa é a elevação do grau de escolaridade, visto que mulheres pobres e com baixa escolaridade tem mais dificuldades de inserção no mundo do trabalho do que aquelas com mais escolarização (ABRAMO, 2006). Foi feito um levantamento de alunas que não tinham escolaridade mínima para concluírem o curso que se matricularam. Desta forma, as mesmas foram encaminhadas para escolas de EJA e CEBEEJA. Das 50 mulheres que estavam frequentando regularmente os cursos, 21 estavam estudando para aumentar o grau de escolaridade, ou seja, $42 \%$.

Em relação à pesquisa das alunas egressas, das 39 concluintes de Auxiliar de Cozinha, 23 responderam ao questionário, enquanto das 11 concluintes de Costureira, 10 responderam.

Quando questionadas a respeito da importância das disciplinas básicas para o crescimento profissional e pessoal, $100 \%$ das entrevistadas julgou muito satisfatória. Entre as alunas de Auxiliar de Cozinha, apenas 35\% alegaram ter uma profissão antes de ingressar no Mulheres Mil. Durante o período do curso, $39 \%$ delas estava trabalhando. Após a conclusão do curso, $52 \%$ estão trabalhando, mas destas, apenas $8 \%$ está trabalhando na área que se profissionalizou. Em relação às alunas de Costureira, $40 \%$ afirmaram ter uma profissão antes de ingressar no Mulheres Mil. Durante o período do curso, 30\% delas estava trabalhando. Após a conclusão do curso, $60 \%$ está trabalhando, e destas, $50 \%$ está trabalhando na área que se profissionalizou. Considerando as egressas dos dois cursos, em relação ao aumento do grau de escolaridade, $45 \%$ das entrevistadas voltaram a estudar durante o Programa para elevar a escolaridade; destas, até o momento da pesquisa, $66 \%$ havia concluído os estudos ou estava cursando. Após o término dos cursos, $48 \%$ fizeram ou estão fazendo outros cursos e $39 \%$ ainda mantiveram alguma ligação com o IFPR por meio de outros Programas, como o Pronatec, por exemplo.

Em relação à satisfação das alunas assistidas pelo Mulheres Mil no IFPR Campus Paranavaí, observou-se elevado grau de satisfação e contentamento em relação ao Programa. A fala de algumas alunas em depoimento demonstram os aspectos positivos do Programa:

“O MM fez eu renascer!”

"Mudou a minha vida."

"É ótimo, aprendi muitas coisas."

"O curso é muito bom, e espero que o curso abra portas de emprego para eu conquistaro meu sonho da casa própria." 


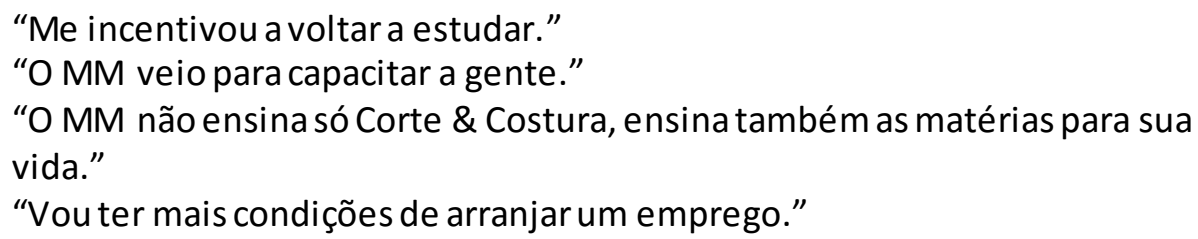

Outro fator verificado foi que as mulheres participantes mudaram a sua perspectiva de vida e tinham orgulho de estudar e de estar em um Programa que as valorizassem. $O$ depoimento de uma aluna demonstra isto:

\section{"Quando visto esta camisa me sinto importante, pois sei que vou aprender alguma} coisa."

Apesar de ser a primeira experiência de aplicação do Mulheres Mil no IFPR - Campus Paranavaí, acredita-se que vários fatores contribuíram para que as alunas gostassem do Programa: disciplinas voltadas para questão do gênero, tais como Direito da Mulher, Valorização da Mulher, elevação da autoestima, linguagem acessível, possibilidade de ter uma profissão, auxílio financeiro para alunas que frequentassem regularmente as aulas, oferta de atividades para valorização da mulher, tais como eventos, palestras, serviços, entre outros. Além disso, o trabalho em grupo, envolvendo todos os servidores do IFPR, bem como instituições parceiras foram fundamentais para o êxito do Programa. Pelo depoimento das mulheres assistidas, pode-se perceber o início de transformação na vida de cada uma, visto que algumas chegaram a alegar problemas de depressão e baixa estima: "eu era dependente de remédios e nunca mais tomei". A participação nas aulas as auxiliou na elevação da autoestima, na mudança de perspectivas, pois passaram a se enxergar capazes de serem alguém, de realizarem sonhos e terem uma vida melhor. Estes resultados também têm sido observados em outros Institutos Federais que aderiram ao Programa (FURTADO et al., 2012; NEVES et al., 2012)

No entanto, apesar de todos os esforços para manter as alunas no Programa e do impacto social que houve na vida de muitas delas, houve algumas dificuldades para manter todas as alunas nos cursos. Das 100 vagas existentes, apenas 50 concluíram. O índice de evasão foi alto, de 50\%, apesar de várias medidas tomadas para mantê-las no Programa, como oferta de alimentação no período das aulas, distribuição de material dos cursos, bolsa de estudo, realização de eventos, comemorações, palestras, atividades de motivação e elevação da autoestima. Os principais motivos, de acordo com pesquisa de evasão realizada, foram: o fato de terem conseguido emprego, horário do curso e necessidade de elevar o grau de escolaridade. Dentre estas, a porcentagem maior observada foi a de terem conseguido emprego durante o curso (20\%), seguido da exigência do Programa em aumentar o nível de escolaridade (15\%). O fato de deixarem o curso devido a um trabalho, do ponto de vista da mulher pode ser um fator positivo, pois aumenta a renda familiar. Contudo, para o Programa foi um impacto negativo, uma vez que o objetivo principal, a profissionalização, não foi cumprido. Desta forma, as desistentes poderiam perder oportunidades melhores de emprego e renda. Outra causa verificada durante o andamento do Programa foi o fato dos cursos terem uma elevada carga horária teórica e as práticas acontecerem apenas na segunda parte do curso. A busca das causas de evasãoé fundamental para compreender as dificuldades deste público feminino e para o êxito de programas que buscam a valorização da mulher. Muitas mulheres de baixa renda são chefes de família (CARVALHO, 1998) ou são coprovedoras do lar (MONTALI, 2006). Desta forma, para muitas é difícil conciliar as atividades 
domésticas e cuidados com os filhos com trabalho e estudo, mesmo diante de incentivos financeiros. O contato com a parte profissionalizante também é um fator importante, visto que era a parte mais es perada do curso pela maioria, mesmo apesar da importância das disciplinas teóricas ofertadas.

Pela análise dos resultados da pesquisa de egressas, percebe-se que há diferenças quando os dois cursos ofertados são comparados. O grau de empregabilidade na área foi maior para as costureiras, uma vez que a demanda de profissionais nesta área é maior na região quando comparado à Auxiliar de Cozinha. Ao final do curso de Costureira, todas aquelas que tivessem interesse tinham vaga disponível no mundo do trabalho. No entanto, devido a dificuldades de algumas delas de conciliar o trabalho com filhos, nem todas foram empregadas, mas tiveram a possibilidade de trabalhar em casa. As alunas que necessitavam elevar o grau de escolaridade, assim o fizeram e muitas continuaram os estudos após conclusão do curso. Percebe-se que o Programa também foi importante para estimular as mulheres a continuarem os estudos, visto que muitas fizeram outros cursos após passarem pelo Programa e várias continuaram a frequentar a Instituição por meio de outros Programas.

\section{CONSIDERAÇÕES FINAIS}

Baseado nos dados obtidos, conclui-se que houve transformação social das participantes do Mulheres Mil, visto que foram observadas mudanças referentes à autoestima, escolaridade, profissionalização, vontade de estudar, o que contribuiu para o cumprimento dos objetivos do Programa. Outros objetivos foram parcialmente cumpridos: empregabilidade das egressas e baixa evasão no Programa. Para as próximas turmas algumas medidas poderiam ser adotadas para melhor cumprimento destes objetivos, tais como: oferta de estágio ao final das aulas para aumentar a segurança das concluintes na profissão e encaminhamento ao mundo do trabalho, oferecer maior assistência para as alunas se manterem no Programa, como atendimento psicológico, melhores condições de transporte, alternar aulas teóricas com as aulas sobre a prática profissionalizante desde o início do curso. No entanto, por ser um grupo vulnerável, como observado, qualquer acontecimento já é motivo de desistência, como problemas com filhos e família, saúde, transporte, emprego, o fato de ter que elevar a escolaridade, entre outros. Em relação à empregabilidade, o maior número de empregos na área certificada foi a de Costureira, que seria um curso a ser ofertado novamente em vista da grande oferta de vagas na região.

Espera-se, por fim, que os resultados obtidos através deste artigo possam subsidiar e melhorar as próximas turmas ofertadas do Programa no IFPR - Campus Paranavaí.

\section{REFERÊNCIAS}

1. ABRAMO, L. Desigualdades e discriminação de gênero e raça no mercado de trabalho brasileiro e suas implicações para a formulação de uma política de emprego. Texto elaborado para o Seminário Nacional: Política geral de emprego: Necessidades, opções, prioridades, OIT, Brasília, 9 e 10 de dezembro de 2004.

2. ABRAMO, L. Desigualdades de gênero e raça no mercado de trabalho brasileiro. Ciência e Cultura, v.58, n.4, p. 40-41, 2006.

3. BRASIL. Ministério da Saúde. Centro de Documentação do Ministério da Saúde. Assistência 
Integral à Saúde da Mulher: bases de ação programática. Brasília, DF, 1984.

4. BRASIL. Observatório de Brasil de Igualdade de Gênero. 2012. Disponível em: < http://www .observatoriodegenero.gov.br/menu/noticias/programa-mulheres-mil-qualificara-mulheresbrasileiras-em-situacao-de-vulnerabilidade-social http://mulheresmil.mec.gov.br/>. Acesso em: 20 Dez. 2012.

5. BRASIL. Programa Mulheres Mil. 2013a. Disponível em: < http://mulheresmil.mec.gov.br>. Acesso em: 30 jan. 2013.

6. BRASIL. Plano Brasil sem Miséria. 2013b. Disponível em: < http://www.brasil.gov.br/sobre/ cidadania/brasil-sem-miseria>. Acesso em: 09 set. 2013b.

7. CARVALHO, L.M.S.S. A mulher trabalhadora na dinâmica da manutenção e da chefia domiciliar. Estudos femininos, v.6, n.1, 1998.

8. FURTADO, F., ANTUNES, J. F., SANTOS, L. M. M., OLIVEIRA, L. A., FERREIRA, R. S., ALVES, B. M. M. Bem-estar subjetivo em participantes do Programa Mulheres Mil, na cidade de BarbacenaMg. HOLOS-ISSN 1807-1600, v.4, p. 178-187, 2012.

9. IBGE. Cidades. 2010. Disponível em: < http://www.ibge.gov.br/cidadesat/painel/painel.php ? codmun=220840 > Acesso em: 15 abr. 2012.

10. IBGE. Pesquisa Mensal de Empregos - PME. 2010. Disponível em: <http://www.ibge.gov.br/home/estatistica/indicadores/trabalhoe rendimento/pme_nova/M ulher_Mercado_Trabalho_Perg_Resp.pdf> acesso em: 29 ago. 2014.

11. MADALOZZO, R., MARTINS, S.R., SHIRATORI, L. Participação no mercado de trabalho e no trabalho doméstico: homens e mulheres têm condições iguais? Estudos Feministas v.18, n.2, p. 547-566, 2010.

12. MONTALI, L. Provedoras e co-provedoras: mulheres-cônjuge e mulheres-chefe de família sob a precarização do trabalho e o desemprego. R. bras. Est. Pop., São Paulo, v. 23, n. 2, p. $223-$ 245, jul./dez. 2006.

13. NEVES, R. M., PAUL, E. C., ALMEIDA, G. S. D. Programa Mulheres Mil: um convite à inclusão social, econômica e ambiental, no IFSC Campus Gaspar/SC. Revista Técnico Científica do IFSC, 1(3), 2012

14. OLIVEIRA, A.A., ARRUDA, S.F.A. A influência de gênero nas dificuldades da mulher no mercado de trabalho. Anais do III Seminário Nacional Gênero e Práticas Culturais, Olhares diversos sobre a diferença, 2011.

15. OLIVEIRA, P.R., SCORZAFAVE, L.G., PAZELLO, E.T. Desemprego e inatividade nas metrópoles brasileiras: as diferenças entre homens e mulheres. Nova Economia, v.19, n.2 p. 291-324, 2009.

16. SANCHES, S., GEBRIM, V.L.M. O trabalho da mulher e as negociações coletivas. Estudos Avançados 17(49); 99-116, 2003.

17. SOARES, S. S. D. O perfil da discriminação no mercado de trabalho - homens negros, mulheres brancas e mulheres negras. Brasília: IPEA, novembro de 2000. (Texto para Discussão, 769). A mulher trabalhadora na dinâmica da manutenção e da chefia domiciliar. Estudos feministas, v.6, n.1, 1998. 